\title{
Effect of Adapted Game-Aided Physical Education Program on the Motor Skills of Children with Autism Spectrum Disorders: Longitudinal Case Study
}

\author{
Sinan Akı1 ${ }^{1, *} \&$ Hulusi Alp ${ }^{2}$ \\ ${ }^{1}$ School of Physical Education and Sports, Kütahya Dumlupınar University, Kütahya, Turkey \\ ${ }^{2}$ Faculty of Sports Science, Süleyman Demirel University, Isparta, Turkey \\ *Correspondence: School of Physical Education and Sports, Kütahya Dumlupınar University, Kütahya, Turkey. Tel: \\ 90-505-824-5232. E-mail: s_akin78@yahoo.com
}

Received: June 18, 2019

Accepted: July 24, 2019 Online Published: August 5, 2019

doi:10.5430/jct.v8n3p63

URL: https://doi.org/10.5430/jct.v8n3p63

\begin{abstract}
The aim of this study is to reveal the effect of long term adapted game aided physical education intervention program conducted on an individual with ASD and to conserve the achieved skills. The participant was fourteen years old during study and was fifteen years old when research was completed. The study took 15 months in total including 12 months of implementation process and 3 months of interval before retention test conducted on the participant. The Short Form of $2^{\text {nd }}$ version of Bruininks-Oseretsky Motor Proficiency Test (BOT-2 SF) was used as a measuring set. Obtained data were evaluated graphically. According to the obtained data, we determined a development but BOT-2 SF started in different periods in 8 sub-dimensions under the title of fine and gross motor skills. When permanency test was obtained after an interval of 3 months for examined intervention program, it was clear that all skills except power sub-dimension were conserved. There was a decrease in a certain amount only in power sub-dimension. In the light of all these consequences, we can say that even though it is late, adapted intervention programs conducted on the individuals with ASD affect motor skill levels positively and it can be said that this development will be effective in increasing life quality of the individuals with ASD.
\end{abstract}

Keywords: adapted intervention program, autism spectrum disorder, bruiniks-oseretsky motor proficiency test, motor skill, quality of life

\section{Introduction}

Autism Spectrum Disorder (ASD) is a characterized natal neurodevelopmental disorder and demonstrates its symptoms in first three years of life, characterised under the title of diffused developmental disorder and getting an increase in prevalence nowadays by displaying improper communication and social interactions with restricted and repetitive behaviours (American Psychiatric Association, 2016). After all, the delays or deficiencies in motor skills are most common and frequent behaviours in the individuals with autism spectrum disorder, even though motor skills disorders are not one of the main characteristics of autism spectrum disorder (Fournier, et al., 2010;Downey \& Rapport, 2012). It has been asserted that problems in performed motor skills besides linguistic, social and intellectual differences sighted in the individuals with ASD could also be an indicator of ASD (Staples \& Reid, 2010; Bhat et al., 2011; Breslin \& Rudisill, 2011; Whyatt \& Craig, 2012; Liu \& Breslin, 2013a; Mcphillips, 2014).

In some researches conducted on the individuals with ASD, there are problems in motor skills such as visual motor deficiency, handcraft, problem in movement skills, balance, coordination, agility and low power weakness (Pan et al., 2009; Staples \& Reid, 2010; McCleery et al., 2013). According to the results of many current researches, it was also determined that individuals with ASD have delay or deficiency in motor skills compared to their peers who show typical development (Ghaziuddin \& Butler, 1998; Ming et al., 2007; Dewey et al., 2007; Provost et al., 2007a; Provost et al., 2007b; Green, et al., 2009; Matson et al., 2010; Lloyd et al., 2011; Bhat, 2012; Whyatt \& Craig, 2012; Lane et al., 2012; Mattard-Labrecque et al., 2013; Liu \& Breslin, 2013b; Pan, 2014; Zikl et al., 2016; Choi et al., 2018). Even though all development areas and their speed of development are different from each other, they have 
interactions with each other (Thelen, 2005; Haywood \& Getchell, 2014). The studies on ASD also support this theory. For example, Mody et al. (2017) revealed that corrupted gross skills have a close relationship with recipient language skill. In another study, it has been revealed that the schoolchildren with ASD have more deficiency in social communicational skill than the children with weak motor skills. (MacDonald et al., 2013). The retrospective analysis of clinic data reported that there is a relationship between motor skill and social functions (Ming et al., 2007; Holloway et al., 2018).

There is a delay in the fine and gross skills of the children with ASD and this delay increases continuously with the age. Unfortunately, motor skills and physical activities are neglected in the areas such as psychology (Rosenbaum, 2005) and accordingly the focal point of intervention planning consists of deficiency in social communication areas, one of the diagnostic traits of ASD (Flanagan et al., 2012) and also typical behaviour problems (Vismara \& Rogers, 2010; Lloyd, 2011; MacDonald et al., 2013). Acquired motor skills have a positive effect on other areas of development such as cognitive development (Piaget, 1964) and social development (Gallahue et al., 2012) and, early developed motor skills cause an increase of other areas of development (Lobo \& Galloway, 2008). Early diagnosis of motor proficiency level is important with regard to the implementation of the intervention program aimed at target by identifying specific deficiencies in individual's development (Piek et al., 2012). Early motor delays in children with ASD have an effect especially on social disorder in first two years of life. Therefore, evaluations performed at the right time for addressing the motor disorders are very important with regard to effective interventions (Bhat et al., 2011; Gkotzia et al., 2017). LeBarton and Iverson (2016) asserted that motor development has potential effects on developing communication and early developed gross motor skills can support developments in other areas and so targeting at the motor skills in early intervention program has positive effects in many implications. In another study, Piek et al. (2012) expressed that intervention programs not only develop motor skills but also prevent or decrease health, learning and psychological problems related to weak motor proficiency.

There is a powerful relationship between motor proficiency and physical activity (Lubans et al., 2010; Akın \& Acet, 2017). Especially motor skill interventions help to develop motor skills (Wrotniak et al., 2006) and it is considered that it increases the potential of developing social skills and probability of participation in physical activity. However, even though there are many researches in literature showing that motor development level is a foresight indicator for ASD diagnosis, there aren't many intervention studies aiming at motor skill deficiencies of individuals with ASD (Colombo-Dougovito \& Block, 2019).

In our study, the determination of the effect of long term adapted physical education program on motor skill level of an individual with ASD and the permanency of later implementation's effects was aimed.

\section{Material and Method}

\subsection{Research Model}

This research is an experimental study. Inter-behavioral multiple probe design of single-subject research models was used. The research lasted fifteen (15) moths in total.

\subsection{Research Group}

One child with autistic characteristics in the Autistic Children and Education Centre participated in the research. Parent consent for participation of the child to the researched was taken.

\subsection{Information about the Participant}

In the interview with the parents to gather information about B.B, we learned that the child was diagnosed with mild autism spectrum disorder at the age of 3 by the result of an investigation during research by a special psychiatrist. Right after diagnosing with autism, the child was put to a special education and rehabilitation centre to provide opportunity to take education with the parents. When the child was 7 years old, he also started to go to an education and implementation centre where autistic children get education and training. When observing B.B.'s motor skills before the study, walking skill, one of the locomotor skills, was seen as that he acquired his walking habit by turning his right leg inward fifteen (15) degrees while his left leg was pointing opposite direction. After the examination, it was revealed that he had no running skill. It was observed that while in ascending ladder skill, right-left leg were ascending rhythmically, in descending skill, he could not perform it rhythmically as right-left leg. In climbing skill, it was observed that he could not perform climbing behaviour to wall mounted kit. It was observed that he could not perform single foot and both feet vertically and leaping forward skill. It was observed that he could not perform the skill of standing in balance on one foot more than one second. It was observed that he was weak in throwing and 
grabbing skills as of the manipulative skills. It was observed that he performed retreating behaviour when we threw plastic ball towards him. It was concluded after interviewing with the parents that B.B had not participated in any adapted movement or physical activity before the study. At the end of the study, the participant became 15 years old.

\subsection{Ethical Considerations}

The participant's family was informed about the participant's current level of motor development and the intervention program and informed consent statement was taken.

\subsection{Data Collection Tool}

Second version of Bruininks-Oseretsky Motor Proficiency Test (BOT-2 SF) was used to measure motor skill levels of the participant (Bruininks \& Bruininks, 2005). BOT-2 had been used to measure motor skill levels of the individuals with ASD in prior studies (Gabriels et al., 2012; Mattard-Labrecque, et al., 2013; Hilton, et al., 2014; Lourenço et al., 2015). BOT-2 is a tool used for educators, treatment specialists and researchers to evaluate motor skill of the children, to evaluate and prepare motor development program, to determine and evaluate various motor function disorders and developmental delays. Test materials were designed in a manner of easing the evaluation and implementation, providing implementation opportunity and attention of the children.

The measurements weren taken by using Short Form of Bruininks-Oseretsky Motor Proficiency Test-2, composed of fourteen (14) skills as part of 8 Sub-Tests. Drawing Line Along the Road and Folding Paper skills were performed as to identify Motor Skill Sensitivity as the first Sub-test and total value of these measurements was taken. The total value of Square Copying and Star Copying skills was taken to evaluate Motor Skill integration as the second Sub-test. Dexterity as the third Sub-test was evaluated with Change Giving skill. The total value of Toe Touching on the Same Side and Changing sides by Jumping with Arm and Leg on the Same Side skills were applied to evaluate Bilateral Coordination as the fourth Sub-test. The total of Standing on Balance Board on One Foot and Walking Foot by Foot on the Line skills was taken to evaluate Balance as the fifth Sub-test. Running Speed and Agility as the sixth Sub-test were evaluated with Jumping on One Foot. The total of Grabbing the Ball with Both Hands and Bouncing the Ball with One Hand by Changing Hands was taken to evaluate Upper-Limb Coordination as the seventh Sub-test. Strength as the eighth Sub-test was evaluated with Standing Long Jump and Sit-up Skills.

Every measurement lasted between 20 and 60 minutes depending on the willingness and attention of the individual. Depending upon the willingness of the individual, we asked him to get attention again by pausing and perform other skill. After the first measurement obtained from the participant, the second measurement was in the second month, the third measurement in the fourth month, the fourth measurement in the eighth month and the fifth measurement in the twelfth month to observe the effect of adapted physical education program after the implementation. At the end of the twelve (12) month process, adapted physical education studies finished and routine studies continued. After three (3) month interval, the sixth and final measurement from the participant was taken to see the long term effect of twelve (12) month program.

\subsection{Implementation Protocol}

This program was prepared suitably for development levels of the autistic child participated in the research. Prepared program was implemented through twelve (12) months by a specialist researcher at the field of autistic children and movement gradient. 
Table 1. Monthly Plan Sample

\begin{tabular}{|c|c|c|}
\hline Objectives & Acquisition & $\begin{array}{l}\text { Methods and } \\
\text { techniques of } \\
\text { learning and } \\
\text { teaching } \\
\end{array}$ \\
\hline $\begin{array}{l}\text {-to make eye contact } \\
\text {-to be able to follow the model } \\
\text {-to perform a commands specifying a } \\
\text { single operation } \\
\text {-to recognize parts of the body }\end{array}$ & $\begin{array}{l}\text { 1. Provides eye contact with the "Look at me" command } \\
\text { 2. Performs a simple command (sit, get up, take, come, etc.) } \\
\text { with help. } \\
\text { 3. Moves the requested part of the body. }\end{array}$ & $\begin{array}{l}\text { Learning by doing, } \\
\text { learning by } \\
\text { experience, } \\
\text { expression, } \\
\text { demonstration }\end{array}$ \\
\hline $\begin{array}{l}\text {-to make walking exercises } \\
\text {-to simulate walks shown }\end{array}$ & $\begin{array}{l}\text { 1. Walks freely. } \\
\text { 2. Walks by moving to the beat. } \\
\text { 3. Walks between two parallel lines. } \\
\text { 4. Walks backwards. } \\
\text { 5. Walks edgeways. } \\
\text { 6. Walks with big steps. } \\
\text { 7. Walks by stepping certain shapes. } \\
\text { 8. Walks with an object in hand. } \\
\text { 9. Walks against the obstacles. } \\
\text { 10. Imitates the walking's of the teachers that he shows } \\
\text { 11. Imitates to walk like lion, bear, wolf, duck tec. }\end{array}$ & $\begin{array}{l}\text { Learning by doing, } \\
\text { learning by } \\
\text { experience, } \\
\text { expression, } \\
\text { demonstration }\end{array}$ \\
\hline $\begin{array}{l}\text {-to imitate walking shown } \\
\text {-to perform running exercises }\end{array}$ & $\begin{array}{l}\text { 1. Runs freely. } \\
\text { 2. Runs by moving to the beat. } \\
\text { 3. Runs towards the target. } \\
\text { 4. Runs on the line. } \\
\text { 5. Runs edgeways. } \\
\text { 6. Runs backwards. } \\
\text { 7. Runs between the obstacles. } \\
\text { 8. Runs with an object in hand. } \\
\text { 9. Runs on the track specified. }\end{array}$ & $\begin{array}{l}\text { Learning by doing, } \\
\text { learning by } \\
\text { experience, } \\
\text { expression, } \\
\text { demonstration }\end{array}$ \\
\hline $\begin{array}{l}\text {-to make leap and coordination exercises } \\
\text {-to make jumping exercises }\end{array}$ & $\begin{array}{l}\text { 1. Jumps with single and double foot inside the shapes painted } \\
\text { on the ground. } \\
\text { 2. Jumps single and double outside of the shapes painted on the } \\
\text { ground. } \\
\text { 3. Jumps over an object in front. } \\
\text { 4. Jumps over the objects ranked in equal intervals. } \\
\text { 5. Jumps off the device in a certain height. } \\
\text { 6. Jumps over the obstacle in a certain height with both feet. }\end{array}$ & $\begin{array}{l}\text { Learning by doing, } \\
\text { learning by } \\
\text { experience, } \\
\text { expression, } \\
\text { demonstration }\end{array}$ \\
\hline
\end{tabular}

\subsection{Statistics}

Because the number of participants joining in this research is only one (1), no statistics were implemented to the data obtained. Raw data obtained were recorded and then converted to run chart to reveal the change occurred in fifteen (15) months process by converting to dot point suitable for the scale protocol. 


\section{Results}

\subsection{Fine Motor Skill}

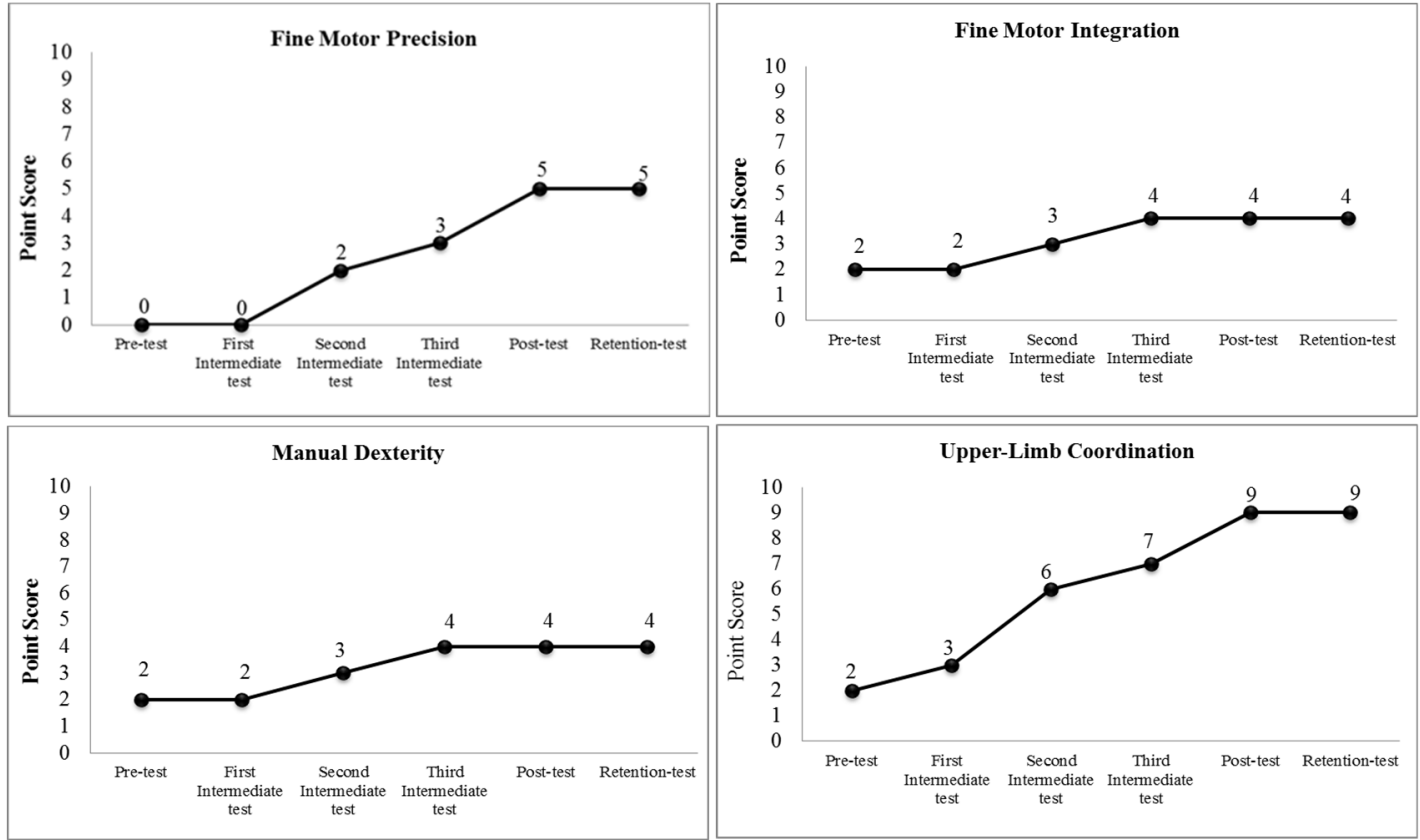

Figure 1. Fine Motor Skill Subtests

According to the results of Bruiniks-Oseretsky Motor Proficiency Test (BOT-2 SF) belonging to the participant, while the first development was observed in the first intermediate-test executed in the $8^{\text {th }}$ week in Upper-Limb Coordination sub-dimension, first development in other sub-dimensions was observed in the second intermediate-test executed in the 16th week. The development in skill level of the participant continuously accelerated vertically until post-test executed in the $12^{\text {th }}$ month in Fine Motor Precision and Upper-Limb Coordination sub-dimensions. While there was vertical acceleration until the $3^{\text {rd }}$ intermediate-test executed in the $8^{\text {th }}$ month in Manual Dexterity and Fine Motor Integration sub-dimensions, the development started to show horizontal movement after this measurement. However, according to the results of the retention test executed after an interval of 3 months, the development occurred in all skill sub-dimensions was conserved in despite of the interval (Figure 1).

\subsection{Gross Motor Skill}

Examining sub-dimension values of Gross Motor Skill, while the first development in Balance sub-dimension was observed in the first intermediate-measuring results executed in the $8^{\text {th }}$ week, it was observed in Bilateral Coordination, Running Speed and Agility and Strength sub-dimensions in the $16^{\text {th }}$ week $\left(2^{\text {nd }}\right.$ intermediate-test). While the developmental acceleration in Running Speed and Agility, Balance and Strength sub-dimensions continued until $12^{\text {th }}$ month, the developmental acceleration in Bilateral Coordination sub-dimension continued until the $3^{\text {rd }}$ intermediate-test in the $8^{\text {th }}$ month and continued its horizontal movement until next measurements. When comparing the retention test results with the last measurement in the twelfth (12) month, it was observed that the development was conserved in Bilateral Coordination, Running and Agility and Balance sub-dimensions, whereas it was observed that there was some decline in Strength dimension (Figure 2).

In addition, it was observed that while the participant was unable to perform many skills used in daily life at the beginning of the intervention process (such as climbing up and down the independent ladder, cycling, button buttoning ...), he was able to do these skills at the end of the process. 


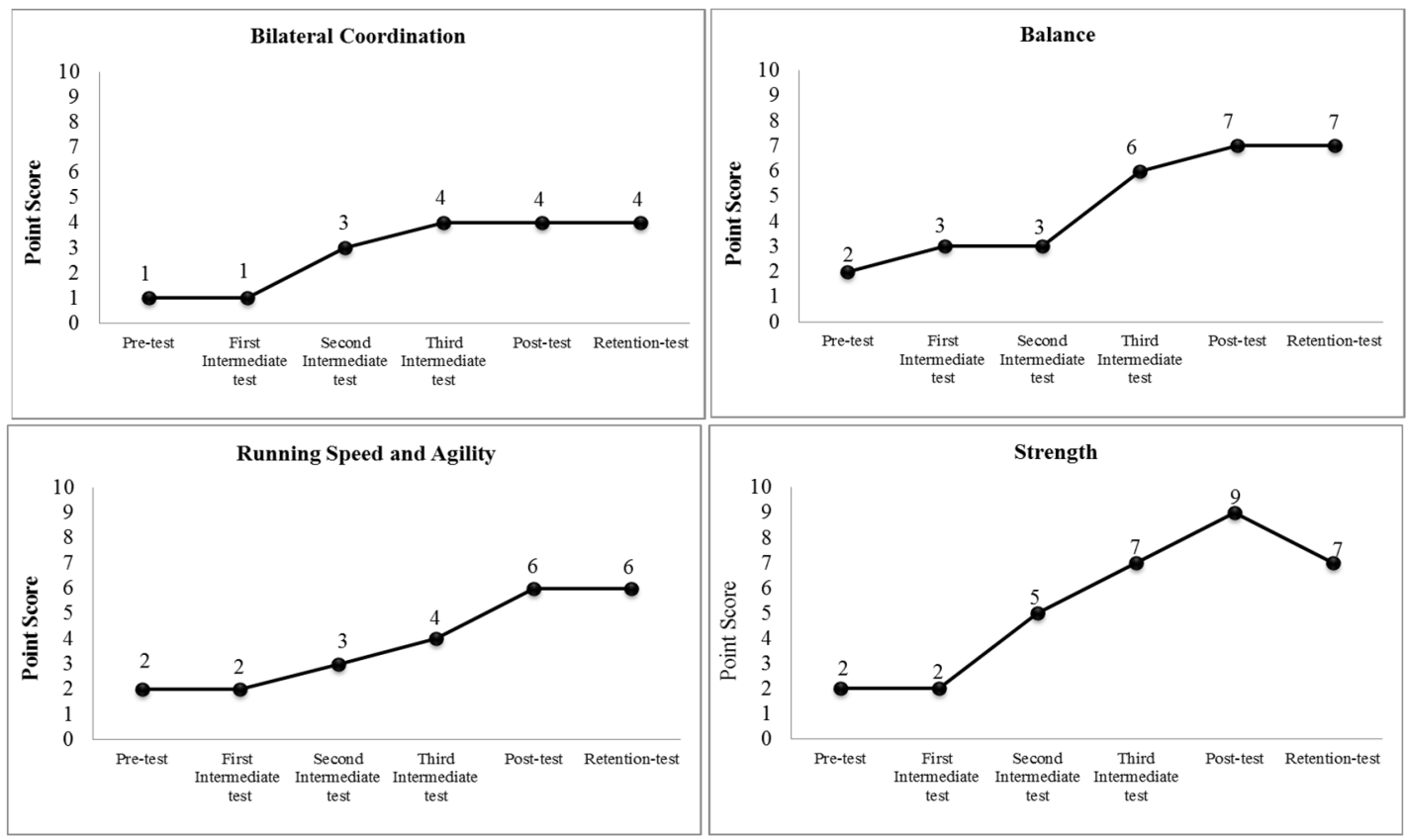

Figure 2. Gross Motor Skill Sub-tests

\section{Discussion}

LeBarton and Iverson (2016) asserted that motor development has potential effects on developing communication and early developed gross motor skills can support the developments in other areas and therefore targeting at motor skills in the intervention programs has many positive effects. Many studies revealed that there is a relationship between motor proficiency and physical exercise (Lourenço et al., 2015). In the research conducted, the effect of physical education program supported with long term implemented game on motor development of an individual with autism was examined and the data revealed that this program has positive effect on fine and gross motor skills of the individual with autism.

In our study, it was determined that there were improvements in both gross and fine motor skills. In the study of Bremer and Lloyd (2016), the development in both motor proficiency level and social skills were determined following intervention consisting 2-6 week educational blocs conducted on the children with ASD in the age range of 3-7 years. In another study, 10 week water exercise intervention was performed for 5-9 years children with ASD within the scope of the strategies developed for education and treatment of the children with Disorders Related Autistic and Communication. This intervention program provided significant developments in both aquatic movement skills and social behaviours (Pan, 2010). In another study, the effectiveness of an intensive motor skill intervention on motor skills was measured. It was confirmed that there was development in a significant level in object control, locomotor and balance skills in the result of intervention process (Ketcheson et al., 2017). In another study by Bremer et al. (2014), while experiment group managed to get significant outcomes in the area of gross motor skill, no significant development was recorded in social skills and adapted behaviour. In the study by Lourenço et al. (2015), it was determined that trampoline exercises positively affected motor proficiency. All these studies support the result of our study.

The results of retention test executed with the aim of determining whether the skills achieved at the end of a twelve (12) month program were conserved after a 3 month interval or not showed that they were conserved to a large extent.

Remarkable human performance is generally based on motor skills and after once acquired, they are conserved extended period of time (Hikosaka, et al., 2002). Motor Movement Memory System is an information network as part of long term memory. This memory is a store providing certain motor skills to be created. The movements expected to perform rhythmic and in certain speed in coordination with the whole body with upper and lower extremities require intensive functioning of the main management system. However, after acquired skills have been 
stored in motor movement memory with adequate repetitions, they function automatically without needing the main management system (Cinan, 2001).

In the study by Hikosaka et al. (2002), it was determined related to the retention of motor skills in monkeys and humans that acquired skills were conserved according to the test results after the process of 16 months. In another study conducted by Akın et al., it was confirmed that adapted badminton exercises conducted on the children with Autism affected the children's attention levels positively and in the period after the intervention process this development was conserved (Akın, et al., 2017). In another study by Akın and Acet examining the effect of the duration of the intervention program on motor retention, the results showed that the motor retention increases in direct proportional to the intervention process duration. The results of the study by Altunsöz and Goodway (2016) aiming at the effect of the successful kinaesthetic training with the children in preschool on motor proficiency of disadvantageous children in preschool showed that acquired skills were also conserved after the interval in research process. The results of all these studies support our results regarding retention.

\section{Conclusion}

As a result; autistic children show deficient or underdeveloped motor skill performances compared to their peers with typical development. Many studies have been done to reveal this situation up to day. However, while it is still discussed whether the delay or deficiency in motor skill levels is a tool with regard to the autism diagnosis or not, that the individuals have delay in motor development is a substantiated truth. Therefore, not only the behavioural development but also motor skills development is so important for children to live freely. Also, besides the development in motor skill in autistic individuals with specially prepared intervention program, the conservation of motor skills saved to motor movement memory system within the context of long term memory is important. The findings belonging to this research show that the development in motor skills was conserved. However, in previous studies, it was determined that there are decreases in mobility level as inversely proportional with increasing age in the individuals with autism. This can be the reason for the low level of motor development.

In many studies, it has been revealed that the motor development of individuals with ASD is retarded. As in other development areas, when they receive direct and intensive instructions, they show positive developments in the field of motor development.

In the light of all these results and researches, we can say that delay and deficiency in motor development can be reduced to minimum with the intervention programs designed suitably to sub-dimensions of the development parallel to the diagnosis of the individual with autism.

\section{References}

Akın, S., \& Acet, M. (2017). Okul Öncesi Çocukların Temel Motor Beceri Gelişiminde Eğitsel Oyunların Akut ve Kronik Etkisi. Lap Lambert Academic Publishing, Bau Bassin, Germany.

Akın, S., Kılınç, F., Söyleyici, Z. S., \& Göçmen, N. (2017). Investigation of the Effects of Badminton Exercises on Attention Development in Autistic Children. European Journal of Physical Education and Sport Science, 3(12), 106-118. http://dx.doi.org/10.5281/zenodo.1068394.

Altunsöz, I. H., \& Goodway, J.D. (2016). SKIPing to motor compotence: the influence of project succesful kinesthetic instruction for preschoolers on motor compotence of disadvantaged preschoolers. Physical Education and Sport Pedagogy, 21(4), 366-385. http://dx.doi.org/10.1080/17408989.2015.1017453

American Psychiatric Association (2016). Diagnostic and statistical manual of mental disorders: DSM-5. Washington, DC: American Psychiatric Association, USA.

Bhat, A. N., Galloway, J. C., \& Landa, R. J. (2012). Relation between early motor delay and later communication delay in infants at risk for autism. Infant Behavior and Development, 35(4), 838-846. https://doi.org/10.1016/j.infbeh.2012.07.019.

Bhat, A. N., Landa, R. J., \& Galloway, J. C. (2011). Current perspectives on motor functioning in infants, children, and adults with autism spectrum disorders. Physical therapy, 91(7), 1116-1129. https://doi.org/10.2522/ptj.20100294.

Bremer, E., \& Lloyd, M. (2016). School-based fundamental motor-skill intervention for children with autism-like characteristics: an exploratory study. Adapted Physical Activity Quarterly, 33(1), 66-88. 
https://doi.org/10.1123/APAQ.2015-0009.

Bremer, E., Balogh, R., \& Lloyd, M. (2014). Effectiveness of a fundamental motor skill intervention for 4-year-old children with autism spectrum disorder: a pilot study. Autism 19(8), 980-991. https://doi.org/10.1177\%2F1362361314557548.

Breslin, C. M., \& Rudisill, M. E. (2011). The effect of visual supports on performance of the TGMD-2 for children with autism spectrum disorder. Adapted Physical Activity Quarterly, 28, 342-353.

Bruininks, R., \& Bruininks, B. (2005). Bruininks-Oseretsky Test of Motor Proficiency (2nd ed.). Minneapolis, MN: NCS Pearson.

Choi, B., Leech, K. A., Tager-Flusberg, H., \& Nelson, C. A. (2018). Development of fine motor skills is associated with expressive language outcomes in infants at high and low risk for autism spectrum disorder. Journal of neurodevelopmental disorders, 10(14), 1-11. https://doi.org/10.1186/s11689-018-9231-3

Cinan, S. (2001). Çoklu Bilgi İşlem Sistemi Olarak İnsan Belleğinin İşleyişi ve Öğrenme, Psikoloji Çalışmaları, 22, 81-95.

Colombo-Dougovito, A. M., \& Block, M. E. (2019). Fundamental Motor Skill Interventions for Children and Adolescents on the Autism Spectrum: a Literature Review. Review Journal of Autism and Developmental Disorders, 6(2), 159-171. https://doi.org/10.1007/s40489-019-00161-2

Dewey, D., Cantell, M., \& Crawford, S. G. (2007). Motor and gestural performance in children with autism spectrum disorders, developmental coordination disorder, and/or attention deficit hyperactivity disorder. Journal of the International Neuropsychological Society, 13(2), 246-256. https://doi.org/10.1017/S1355617707070270

Downey, R., \& Rapport, M. J. K. (2012). Motor activity in children with autism: a review of current literature. Pediatric Physical Therapy, 24(1), 2-20. https://doi.org/10.1097/PEP.0b013e31823db95f

Flanagan, J. E., Landa, R., \& Bhat, A. (2012). Head lag in infants at risk for autism: a preliminary study. American Journal of Occupational Therapy, 66(5), 577-585. https://doi.org/10.5014/ajot.2012.004192

Fournier, K. A., Hass, C. J., Naik, S. K., Lodha, N., \& Cauraugh, J. H. (2010). Motor coordination in autism spectrum disorders: A synthesis and meta-analysis. Journal of Autism Developmental Disorders, 40, 1227-1240. https://doi.org/10.1007/s10803-010-0981-3

Gabriels, R. L., Agnew, J., Holt, K. D., Shoffner, A., Zhaoxing, P., Ruzzano, S., \& Mesibov, G. (2012). Pilot study measuring the effects of therapeutic horseback riding on school-age children and adolescents with autism spectrum disorders. Research in Autism Spectrum Disorders, 6(2), 578-588. https://doi.org/10.1016/j.rasd.2011.09.007

Gallahue, D. L., Ozmun, J. C., \& Goodway J. D. (2012). Understanding motor development: Infants, children, adolescents, adults (7th ed.). International Edition, McGraw-Hill Companies, 461 p., New York, USA.

Ghaziuddin, M., \& Butler, E. (1998). Clumsiness in autism and Asperger syndrome: afurther report. $J$ Intellect Disabil Res, 42, 43-48. https://doi.org/10.1046/j.1365-2788.1998.00065.x

Gkotzia, E., Venetsanou, F., \& Kambas, A. (2017). Motor proficiency of children with autism spectrum disorders and intellectual disabilities: a review. European Psychomotricity Journal, 9(1), 46-69.

Green, D., Charman, T., Pickles, A., Chandler, S., Loucas, T. O. M., Simonoff, E., \& Baird, G. (2009). Impairment in movement skills of children with autistic spectrum disorders. Developmental Medicine \& Child Neurology, 51,311-316. https://doi.org/10.1111/j.1469-8749.2008.03242.x

Haywood, K. M., \& Getchell, N. (2014). Lifespan motor development (6th ed.). Human Kinetics: USA.

Hikosaka, O., Rand, M., Nakamura, K., Miyachi, S., Kitaguchi, K., Sakai, K., Lu, X., \& Shimo, Y. (2002). Long-term retention of motor skill in macaque monkeys and humans. Experimental Brain Research, 147(4), 494-504. https://doi.org/10.1007/s00221-002-1258-7.

Hilton, C. L., Cumpata, K., Klohr, C., Gaetke, S., Artner, A., Johnson, H., \& Dobbs, S. (2014). Effects of exergaming on executive function and motor skills in children with autism spectrum disorder: A pilot study. American Journal of Occupational Therapy, 68, 57-65. https://doi.org/10.5014/ajot.2014.008664

Holloway, J. M., Long, T. M., \& Biasini, F. (2018). Relationships Between Gross Motor Skills and Social Function in Young Boys With Autism Spectrum Disorder. Pediatric Physical Therapy, 30(3), 184-190. https://dx.doi.org/10.1097\%2FPEP.0000000000000505 
Ketcheson, L., Hauck, J., \& Ulrich, D. (2017). The effects of an early motor skill intervention on motor skills, levels of physical activity, and socialization in young children with autism spectrum disorder: A pilot study. Autism, 21(4), 481-492. https://doi.org/10.1177\%2F1362361316650611

Lane, A., Harpster, K., \& Heathcock, J. (2012). Motor characteristics of young children referred for possible autism spectrum disorder. Pediatric Physical Therapy, 24(1), 21-29. https://doi.org/10.1097/PEP.0b013e31823e071a.

LeBarton, E. S., \& Iverson, J. M. (2016). Associations between gross motor and communicative development in at-risk infants. Infant Behavior and Development, 44, 59-67. https://doi.org/10.1016/j.infbeh.2016.05.003

Liu, T., \& Breslin, C. M. (2013a). The effect of a picture activity schedule on performance of the MABC-2 for children with autism spectrum disorder. Research Quarterly for Exercise and Sport, 84(2), 206-212. https://doi.org/10.1080/02701367.2013.784725

Liu, T., \& Breslin, C. M. (2013b). Fine and gross motor performance of the MABC-2 by children with autism spectrum disorder and typically developing children. Research in Autism Spectrum Disorders, 7(10), 1244-1249. https://doi.org/10.1016/j.rasd.2013.07.002

Lloyd, M., MacDonald, M., \& Lord, C. (2011). Motor skills of toddlers with autism spectrum disorders. Autism, 17(2), 133-146. https://doi.org/10.1177/1362361311402230

Lobo, M. A., \& Galloway, J. C. (2008). Postural and object-oriented experiences advance early reaching, object exploration, and means-end behavior. Child Development, 79(6), 1869-1890. https://doi.org/10.1111/j.1467-8624.2008.01231.x

Lourenço, C., Esteves, D., Corredeira, R., \& Seabra, A. (2015). The effect of a trampoline-based training program on the muscle strength of the inferior limbs and motor proficiency in children with autism spectrum disorders. Journal of Physical Education and Sport, 15(3), 592-597. https://doi.org/10.7752/jpes.2015.03089

Lubans, D. R., Morgan, P. J., Cliff, D. P., Barnett, L. M., \& Okely, A. D. (2010). Fundamental movement skills in children and adolescents: Review of associated health benefits. Sports Medicine, 40(12), 1019-1035. https://doi.org/10.2165/11536850-000000000-00000

MacDonald, M., Lord, C., \& Ulrich, D. A. (2013). The relationship of motor skills and social communicative skills in school-aged children with autism spectrum disorder. Adapted Physical Activity Quarterly, 30(3), 271-282.

Matson, J. L., Mahan, S., Fodstad, J. C., Hess, J. A., \& Neal, D. (2010). Motor skill abilities in toddlers with autistic disorder, pervasive developmental disorder-not otherwise specified, and atypical development. Research in Autism Spectrum Disorders, 4(3), 444-449. https://doi.org/10.1016/j.rasd.2009.10.018

Mattard-Labrecque, C., Amor, L. B., \& Couture, M. M. (2013). Children with autism and attention difficulties: A pilot study of the association between sensory, motor, and adaptive behaviors. Journal of the Canadian Academy of Child and Adolescent Psychiatry, 22(2), 139-146.

McCleery, J. P., Elliott, N. A., Sampanis, D. S., \& Stefanidou, C. A. (2013). Motor development and motor resonance difficulties in autism: relevance to early intervention for language and communication skills. Frontiers in integrative neuroscience, 7(30), 1-20. https://doi.org/10.3389/fnint.2013.00030

McPhillips, M., Finlay, J., Bejerot, S., \& Hanley, M. (2014). Motor deficits in children with autism spectrum disorder: a cross-syndrome study. Autism Res. 7, 664-676. https://doi.org/10.1002/aur.1408

Ming, X., Brimacombe, M., \& Wagner, G. C. (2007). Prevalence of motor impairment in autism spectrum disorders. Brain and Development, 29, 565-570. https://doi.org/10.1016/j.braindev.2007.03.002

Mody, M., Shui, A. M., Nowinski, L. A., Golas, S. B., Ferrone, C., O'Rourke, J. A., \& McDougle, C. J. (2017). Communication deficits and the motor system: Exploring patterns of associations in autism spectrum disorder (ASD). Journal of Autism Developmental Disorders, 47, 155-162. https://doi.org/10.1007/s10803-016-2934-y

Pan, C. Y. (2010). Effects of water exercise swimming program on aquatic skills and social behaviors in children with autism spectrum disorders. Autism, 14(1), 9-28. https://doi.org/10.1177/1362361309339496

Pan, C. Y. (2014). Motor proficiency and physical fitness in adolescent males with and without autism spectrum disorders. Autism, 18(2), 156-165. https://doi.org/10.1177\%2F1362361312458597

Pan, C. Y., Tsai, C. L., \& Chu, C. H. (2009). Fundamental movement skills in children diagnosed with Autism Spectrum Disorders and Attention Deficit Hyperactivity Disorder. Journal of Autism Developmental Disorders, 39(2), 1694-1705. https://doi.org/10.1007/s10803-009-0813-5 
Piaget, J. (1964). Developing and learning. In: Ripple, R.E. and Rocastle, V.N. (Eds.), Piaget rediscovered. Ithaca, NY: Cornell University Press.

Piek, J. P., Hands, B., \& Licari, M. K. (2012). Assessment of motor functioning in the preschool period. Neuropsychology Review, 22, 402-413. https://doi.org/10.1007/s11065-012-9211-4

Provost, B., Heimerl, S., \& Lopez, B. R. (2007a). Levels of gross and fine motor development in young children with autism spectrum disorder. Physical \& Occupational Therapy in Pediatrics, 27(3), 21-36. https://doi.org/10.1080/J006v27n03_0

Provost, B., Lopez, B. R., \& Heimerl, S. (2007b). A comparison of motor delays in young children: autism spectrum disorder, developmental delay, and developmental concerns. Journal of autism and developmental disorders, 37(2), 321-328. https://doi.org/10.1007/s10803-006-0170-6

Rosenbaum D. A. (2005). The Cinderella of psychology: the neglect of motor control in the science of mental life and behavior. American Psychologist, 60(4), 308-317. https://doi.org/10.1037/0003-066X.60.4.308

Staples, K. L., \& Reid, G. (2010). Fundamental movement skills and autism spectrum disorders. Journal of Autism Developmental Disorders, 40, 209-217. https://doi.org/10.1007/s10803-009-0854-9

Thelen E. (2005). Dynamic systems theory and the complexity of change. Psychoanalytic Dialogues, 15(2), 255-283. https://doi.org/10.1080/10481881509348831

Vismara, L. A., \& Rogers, S. J. (2010). Behavioral treatments in autism spectrum disorder: What do we know?. Annual Review of Clinical Psychology, 6, 447-468. https://doi.org/10.1146/annurev.clinpsy.121208.131151

Whyatt, C. P., \& Craig, C. M. (2012). Motor skills in children aged 7-10 years, diagnosed with autism spectrum disorder. Journal of Autism Developmental Disorders, 42, 1799-1809. https://doi.org/10.1007/s10803-011-1421-8

Wrotniak, B. H., Epstein, L. H., Dorn, J. M., Jones, K. E., \& Kondilis,V. A. (2006) The relationship between motor proficiency and physical activity in children. Pediatrics 118(6), 1758-1765. https://doi.org/10.1542/peds.2006-0742

Zikl, P., Petrů, D., Daňková, A., Doležalová, H., \& Šafaříková, K. (2016). Motor skills of children with autistic spectrum disorder. In SHS Web of Conferences (Vol. 26, p. 01076). EDP Sciences. 